\title{
PELATIHAN MANEJEMEN KOMUNIKASI MEREK KEPADA PELAKU USAHA DALAM MENDUKUNG CITY BRANDING CIREBON
}

\author{
Suharyanti ${ }^{1}$, Mirana Hanathasia ${ }^{2}$, Ananda Fortunisa ${ }^{3}$ \\ 12 Program Studi Imu Komunikasi, ${ }^{3}$ Program Studi Manajemen, Universitas Bakrie, Jakarta, 12960, \\ Indonesia \\ E-mail: ${ }^{3}$ suharyanti@bakrie.ac.id, ${ }^{2}$ mirana@bakrie.ac.id*, ${ }^{3}$ ananda.fortunisa@bakrie.ac.id \\ DOI: https://doi.org/10.36782/ijsr.v1i02.14
}

\begin{abstract}
Abstrak
Pada 2017 Pemerintah Indonesia mentargetkan sebanyak 8 juta usaha mikro, kecil, dan menengah (UMKM) Indonesia sudah berjualan online pada 2019. Untuk mendukung target pemerintah tersebut Program Studi Ilmu Komunikasi dan Program Studi Manajemen Universitas Bakrie mengadakan pelatihan manajemen komunikasi merek kepada pelaku usaha di Kota Cirebon, Jawa Barat pada 29 Januari 2019 dalam mewujudkan City Branding Cirebon. Tujuan dilaksanakan pelatihan ini adalah untuk membekali pelaku UMKM untuk mengelola merek produk melalui penyusunan konten promosi dengan memanfaatkan platform media baru dan membuat strategi perencanaan media untuk mendukung City Branding Cirebon. Peserta pelatihan ini adalah pelaku UMKM makanan, batik dan kerajinan tangan. Sebanyak 18 pelaku UMKM hadir. Diharapkan dengan mengikuti pelatihan ini produk UMKM Cirebon dapat lebih dikenal dan dapat turut membentuk branding kota Cirebon. Hasil pelatihan memperlihatkan perserta memiliki pengetahuan mengelola merek dengan menggunakan platform media digital. Setelah pelatihan, terdapat satu peserta yang mendapatkan pendampingan pengelolaan merek dari tim pelatihan.
\end{abstract}

Kata Kunci: Cirebon, pelatihan, komunikasi, merek, pemasaran, umkm, city branding

\begin{abstract}
In 2917 Indonesian Government has tergetted 8 millions small-medium enterprises (SME) to go online at 2019. In align with this target, Communication Science Department and Management Department of Universitas Bakrie held a workshop on brand communication management to small-medium enterprises in Cirebon, West Java at 29 January 2019 in order to support Cirebon City Branding. The purpose of the workshop was to equip the SME to manage their product brand through promotion content writing by using new media platform and create media plan strategy to support Cirebon City Branding. The participants of the workshop were from food, batik and handycraft business. There were 18 participants. By attending this workshop, in the future, it was expected that the participants can implement the content given therefore their product will be known and it can create the Cirebon City Branding. The result of the workshop showed that participants had broadened their knowledge about brand management by using digital media platform. After the workshop, there was one participant who had received mentoring from the instructor team to manage her brand.
\end{abstract}

Keywords: Cirebon, workshop, communication, brand, marketing, small-medium enterprises, city branding 


\section{Latar Belakang}

Untuk mendukung target pemerintah menjadikan 8 juta pengusaha usaha mikro, kecil, dan menengah (UMKM) untuk dapat berjualan secara online pada 2019 (jabar.antaranews.com; kominfo.go.id), Pemerintah Kota Cirebon giat mengadakan pelatihan pemasaran berbasis daring (online) yang dilakukan sejak tahun 2017.

Dibutuhkan strategi komunikasi pemasaran yang efektif Untuk dapat memasarkan produk secara online. Tujuan dari strategi komunikasi pemasaran adalah untuk meraih keselarasan dalam pengiriman pesan dari pemilik merek kepada konsumen sehingga mendatangkan dampak positif seperti terciptanya kesadaran merek (brand awareness) dan peningkatan penjualan (Clow dan Baack, 2012).

Pesan dan kanal media memiliki peran penting dalam menjangkau konsumen. Untuk menjangkau konsumen, beragam atribut dan varian komunikasi digunakan seperti iklan, public relations/humas, sales promotion, direct events, events and sponsorships, point of sale, digital media dan aspek komunikasi kemasan (Moriarty, et.all, 2015).

Target pemerintah ini tidak terlepas dari adanya perkembangan penggunaan media digital yang terus meningkat setiap tahunnya. Di tengah maraknya penggunaan media digital, media sosial memegang peranan penting untuk menyebarkan informasi. Terdapat lebih dari 106 juta orang Indonesia pengguna sosial media pada tahun 2017, 85\% diantaranya mengakses media sosial melalui telepon genggam (inet.detik.com).

Melihat angka pengguna media sosial yang cukup besar, maka konten yang disampaikan haruslah dapat menarik perhatian khalayak. Agar sebuah iklan menjadi efektif menyasar target khalayak, maka perlu memperhatikan dua hal yaitu kreativitas dan strategi media (Egan, 2007).

Clow dan Baack (2012) mengatakan bahwa sangat penting untuk membuat pesan yang secara efektif dapat menjangkau target khalayak baik untuk menyasar kognitif, afektif maupun perilaku seseorang.

Saat ini meski sudah banyak pelaku UMKM Kota Cirebon yang sudah memanfaatkan media sosial Instagram dan Facebook sebagai media promosinya, namun tidak banyak dari pelaku UMKM yang melek strategi komunikasi pemasaran. Mereka kurang paham bagaimana menyusun konten dan memilih media yang efektif. Untuk jangka panjang, penggunaan strategi komunikasi pemasaran yang efektif mampu membentuk city branding Kota Cirebon yang baru.

Berdasarkan latar belakang kondisi tersebut, Program Studi IImu Komunikasi Universitas Bakrie dan Program Studi Manajemen memiliki kepedulian untuk memberikan Pelatihan Manajemen Komunikasi Merek Kepada Pelaku Usaha dalam Mendukung City Branding Cirebon. Pelatihan ini diharapkan mampu membekali pelaku UMKM tentang manajemen komunikasi merek melalui penyusunan konten promosi dengan pemanfaatkan media digital dan membuat strategi perencanaan media.

\section{Tinjauan Kegiatan dan Literatur}

\section{A. Komunikasi Pemasaran Terpadu}

Komunikasi pemasaran terpadu adalah upaya organisasi dalam mensinergikan semua saluran komunikasi dalam menyampaikan pesan secara jelas, konsisten dan berpengaruh kuat tentang organisasi dan produk-produknya sehingga menimbulkan keinginan konsumen untuk membeli atau mengkonsumsi produk tersebut (Belch, et.all, 2004).

Moriarty et.al (2015) menyatakan bahwa komunikasi pemasaran terpadu merupakan komunikasi menyeluruh dalam pengiriman pesan atas sebuah merek. Diharapkan pengiriman pesan tersebut dapat memberikan dampak yang positif atas citra merek. 
Elemen komunikasi pemasaran terpadu atau dikenal dengan istilah marketing communication mix mencakup (Belch, et.all, 2004):
- Advertising
- Direct Marketing
- Interactive/ internet marketing
- Sales promotion
- Publicity/ Public Relations
- Personal selling

\section{B. Manajemen Komunikasi Merek}

Komunikasi pemasaran terpadu fokus pada penggunaan elemen komunikasi pemasaran terpadu (Moriarty et.al, 2015). Sementara komunikasi merek tidak hanya berpatok kepada pesan promosi yang dikirimkan melalui elemen komunikasi pemasaran terpadu tetapi juga melibatkan pengalaman yang diberikan oleh sebuah merek kepada penggunanya sehingga terjalin hubungan yang erat antara merek dan penggunanya (Moriarty et.al, 2015).

Pemerekan (branding) itu sendiri adalah fungsi komunikasi yang menjadikan aspek intangible sebuah merek menjadi sesuatu yang tidak terlupakan atau berarti bagi pelanggannya (Moriarty et.al, 2015). Sebuah merek muncul di benak konsumen merupakan akibat adanya kebutuhan, experience dan engagement antara pelanggan dengan merek tersebut.

Terdapat tujuan fungsional ketika komunikasi beradaptasi antar budaya. Penggunaan strategi persuasif dapat mengarah pada adaptasi komunikasi. Ketika suatu situasi mendukung satu komunikator atau satu komunikator yang lebih kuat, komunikator lain memiliki beban untuk beradaptasi (Widiastuti, 2019).

\section{Strategi Perencanaan Media}

Di era perkembangan teknologi saat ini, tidak dapat dipungkiri bahwa penempatan media iklan di internet menjadi sangat berpengaruh dan dapat menyebar dengan cepat. Internet dapat menciptakan buzz dan menyebarkan informasi dari mulut ke mulut (word of-mouth) (Shimp, 2007). Media internet merupakan media interactive periklanan (iklan interaktif). Meski beriklan di internet bisa terbilang lebih murah dan efektif (Shrimp, 2007) dan dapat menyasar khalayak cukup tinggi, interaktif, dan biaya relatif rendah (Kotler dan Keller, 2009) namun efektivitas maksimal akan didapat jika dilakukan penggunaan media secara terintegrasi (Shrimp, 2007).

Beberapa media iklan di media online mencakup (Kotler dan Keller, 2009) website atau situs, microsite, search ads, banner ads atau display ads, Interstitials dan pop-ups, internet-specific ads dan video. Sedangkan social networks mencakup MySpace, Facebook, Linkedln, Path, Line, dan sebagainya (Kotler dan Keller, 2009: 585). Selain itu, Shimp (2007) menambahkan beberapa informasi tentang media periklanan secara online, yaitu web blog atau blog dan Instagram. Jika kekuatan blog berada di narasi maka kekuatan Instagram adalah di foto dan video yang ditampilkannya (wawancara Firzi Abiddin, Pakar Media Sosial, wawancara pada 27 Mei 2015).

Meski penggunaan media memainkan peranan penting dalam menyampaikan pesan, namun isi/pesan itu sendiri juga berperan sangat krusial dalam efektivitas pesan. Isi pesan haruslah unik dan menarik. Pesan dalam sebuah iklan harus mengarahkan konsumen kepada suatu keinginan mencapai suatu personal value bagi konsumen (Clow dan Baack, 2012).

\section{Gambaran Umum}

Kota Cirebon berada di Kabupaten Cirebon Propinsi Jawa Barat. Cirebon dikenal sebagai Kota Udang. Pengukuhan Cirebon sebagai Kota Udang dilakukan di jaman kolonialisme Belanda (tempo.co). Patung udang menempel di atap gedung pemerintahan Kota Cirebon (tempo.co). Pemerekan kota (city branding) kota Cirebon sebagai Kota Udang tidak terlepas dari lokasi wilayah Cirebon yang berada di pesisir 
pantai utara Jawa mengakibatkan udang mudah ditemukan di perairan manapun di Cirebon, baik laut maupun sungai (tempo.co). Udang dijadikan produk makanan yang diolah oleh masyarakat Cirebon. Ada krupuk udang, terasi, petis yang kerap dijadikan buah tangan oleh para pelancong. Selain udang, oleh-oleh khas Cirebon adalah batik ddengan motif khas megamendung yang dibuat di sentra batik rakyat di wilayah Trusmi, Kabupaten Cirebon. Ada juga lukisan kaca yang menjadi ciri khas kerajinan kota Cirebon.

Seiring dengan perubahan iklim dan polusi yang memengaruhi habitat udang di Cirebon mengibatkan temuan udang tidak lagi semudah dulu (tempo.co). Para pelaku atau pembuat makanan olahan pun harus memutar otak untuk bertahan hidup dan mengembangkan usahanya. Terlebih lagi pada 2015, Tol Cipali (Cikopo-Palimanan) resmi dibuka. Jalan tol yang menghubungkan Jakarta - Cirebon dengan waktu tempuh kurang dari tiga jam mengakibatkan banyak warga Jakarta berwisata ke Cirebon. Jika dulu kota Cirebon merupakan kota pesinggahan bagi para pelaku usaha yang akan melanjutkan perjalanan ke kota-kota di Jawa Tengah atau Jawa Timur, kini Cirebon sudah menjadi daerah tujuan wisata.

$\mathrm{Hal}$ ini menjadi peluang bagi pelaku usaha mikro, kecil dan menengah (UMKM) untuk mengembangkan usaha. Tidak menyia-nyiakan kesempatan ini, para pelaku usaha mikro, kecil, menengah (UMKM) menawarkan produk makanan olahan yang beragam. Selain makanan, pengrajin juga mulai memasarkan produk yang lebih beragam sebagai oleh-oleh khas Cirebon. Saat ini terdapat sekitar 1698 pelaku UMKM di Kota Cirebon (disperindagko pumkm.cirebonkota.go.id).

Melihat geliat pelaku UMKM ini, pemerintah kota tidak tinggal diam. Untuk memajukan usaha UMKM, pada 11 Agustus 2018, Pemerintah Kabupaten Cirebon meresmikan Kampung UKM Digital di Desa Tegalwangi, Kabupaten Cirebon. Berbagai pelatihan pemasaran berabasis digital juga kerap dilakukan. Sebelumnya sejak 2017 berbagai pelatihan pemasaran digital kerap dilakukan di kota Cirebon. Tujuannya agar para pelaku UMKM dapat menyesuaikan diri dengan kemajuan teknologi dan tidak kalah saing dengan pelaku usaha yang sudah ada (pikiran-rakyat.com).

\section{Metode Kegiatan}

Beberapa metode yang dilaksanakan dalam kegiatan PkM Pelatihan:

1. Assesment terhadap pelaku usaha, yang bertujuan untuk mengidentifikasi peluang dan tantangan dalam mengelola komunikasi merek pada 28 Januari 2019. Para pelaku usaha :

a. Kuliner: Nasi Jamblang Pelabuhan, Bawang Goreng Mama Rosie, Rengginang Kidal, Bawang Goreng Mama Rossy, Produk Ninik Zam-Zam,

b. Konveksi: Pengrajin Batik

c. Lain-lain: Sabun Yenni, Bengkel Seni Relief Logam Brassco

2. Pelatihan Komunikasi Merek untuk para pelaku UMKM pada 29 Januari 2019. Bertempat di Kantor Dinas Perindustrian dan Perdagangan Kota Cirebon. Pelatihan ini dilakukan untuk tujuan:

a. Memilih tema-tema yang menarik untuk dikomunikasikan,

b. Membuat simulasi mengenai: strategi perencanaan media

3. Pendampingan terkait manjamen komunikasi merek dan strategi perencanaan media kepada salah satu pelaku usaha setelah pelatihan (Mama Rossy)

\section{Pembahasan}

\section{A. Sistematika Proses Pelatihan}

Tahap persiapan. Persiapan dilakukan di Jakarta dan Cirebon. Persiapan yang dilakukan di Jakarta adalah menyiapkan materi pelatihan. Persiapan yang dilakukan di Cirebon adalah melakukan asessmen untuk mendalami permasalahan para pelaku UMKM terkait kesulitan mereka dalam 
mengelola merek dan menyiapkan konten digital.

Hasil assessmen menunjukkan masih banyak pelaku usaha yang menjalankan usahanya secara konvensional. Pelaku usaha tipe ini umumnya adalah pelaku usaha yang sudah berjalan puluhan tahun dan turun menurun diwariskan oleh keluarganya, seperti Pengrajin Batik Masniri di Trusmi. Keluarga Masniri menjalankan usahanya turun menurun sudah lebih dari 47 tahun.
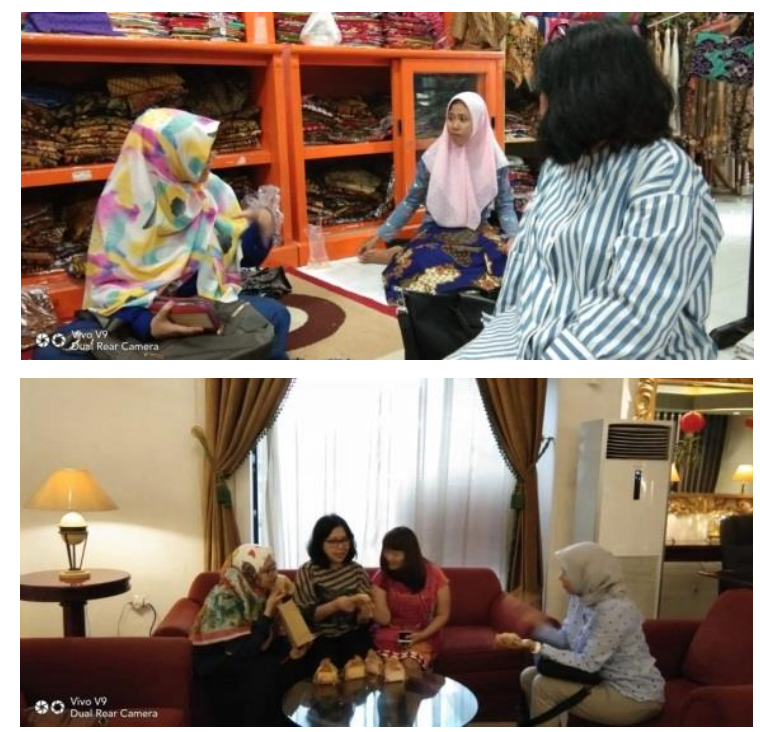

Gambar 1. Assessment kepada Pelaku Usaha (Sumber: Dokumentasi penulis)

Tidak ada merek di batiknya dan tidak ada media yang digunakan untuk memperkenalkan produknya. Setali tiga uang dengan Masniri, demikian juga dengan pelaku usaha nasi jamblang pelabuhan. Sudah hampir 50 tahun warung nasi jamblang ini berdiri, namun dekorasinya tidak berubah dan perluasan wilayah warungnya juga tidak cukup signifikan.

Selain pelaku usaha yang bisnisnya telah dikelola turun menurun, terdapat juga pelaku usaha yang baru dikembangkan beberapa tahun terakhir. Dalam memasarkan produknya, mereka sudah menggunakan media baru seperti menggunakan Instagram.

Tahap pelaksanaan pada 29 Januari 2019, bertempat di kantor Dinas Perindustrian Perdagangan, Koperasi, Usaha Kecil dan Menengah Kota Cirebon. Tim
Pengabdian Kepada Masyarakat (Abdimas) mengadakan kegiatan pelatihan dengan memberikan pemahaman/ materi tentang merek, komunikasi pemasaran terpadu dan strategi pemilihan media, termasuk di antaranya promosi melalui media baru seperti sosial media Instagram, Youtube, dan Facebook. Terdapat 18 peserta hadir dalam pelatihan ini. Pada saat pelatihan peserta diminta untuk membuat narasi untuk memromosikan produknya untuk ditayangkan di media sosial.

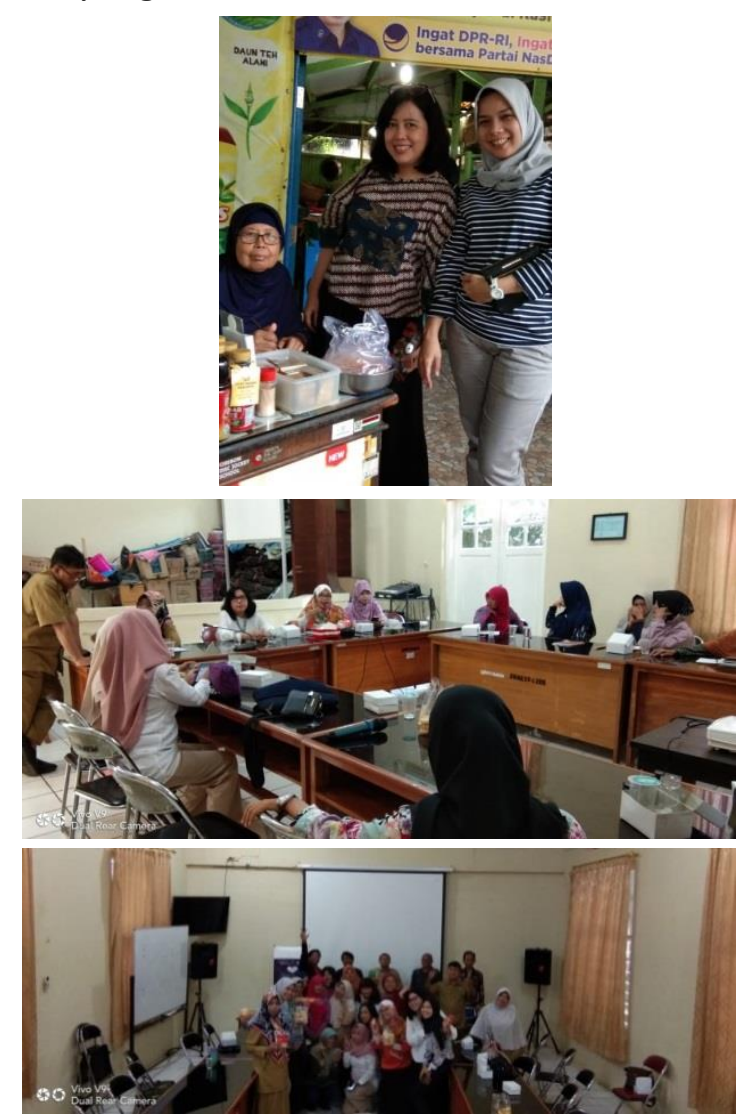

Gambar 2. Kegiatan Pelatihan di Kantor Dinas Perindustrian dan Perdagangan Kota Cirebon

(Sumber: Dokumentasi penulis)

Di akhir pelatihan terdapat diskusi studi kasus/ konsultasi terkait produk-produk peserta seperti Bengkel Seni Relief Logam Brassco, bawang goreng Mama Rossy, Rengginang Kidal, Sabun Yenni, Bawang Goreng Ninik Zam-Zam.

\section{B. Respon Objek PkM}

Secara umum respon dari para peserta pelatihan adalah positif. Peserta mengaku 
senang dengan metode penyampaikan materi yang banyak memberikan contohcontoh konkrit sehingga dapat memberikan gambar yang nyata tentang pemahaman sebuah konsep yang diberikan.

\section{Perubahan Signifikan Setelah Pelatihan}

Di akhir pelatihan peserta merasakan manfaat dan mendapatkan pemahaman lebih baik tentang pengelolaan merek. Salah satu peserta menunjukkan keberlanjutan pembelajaran terkait pengelolaan merek. Untuk mendukung hal tersebut, tim memberikan pendampingan kepada seorang pelaku UMKM. Adalah Mama Rossy, merek produk bawang goreng yang berkonsultasi terkait pemerekan produknya. Aktivitas konsultasi one on one dilakukan melalui aplikasi WhatsApp untuk membahas strategi komunikasi merek Mama Rossy.

\section{Kesimpulan}

Produk khas suatu kota merupakan salah satu elemen city branding. Oleh karena itu produk khas harus dapat diceritakan kepada masyarakat luas dengan pengemasan yang baik. Dalam mengembangkan merek produk maka para pelaku usaha harus mampu mengelola komunikasi merek produk. Merek produk juga harus mampu diasosiasikan dengan merek kota asal sehingga dapat mengangkat merek kota tersebut.

Prodi Ilmu Komunikasi dan Prodi Manajemen Universitas Bakrie hadir di tengah para pelaku usaha Cirebon untuk memberikan pelatihan manajemen komunikasi merek. Kegiatan ini diharapkan dapat terus berlanjut menjadi upaya pengembangan kawasan Cirebon dan sekaligus juga melestarikan industri kecil yang unggul didaerah Cirebon sebagai kekayaan budaya bangsa Indonesia. Ke depannya, diharapkan kegiatan dapat melibatkan unsur masyarakat yang lebih besar dan bersinergi dengan institusiinstitusi terkait yang memiliki kepedulian dan kepentingan yang sama untuk mengembangkan sekaligus melestarikan kekayaan warisan bangsa.

\section{Ucapan Terima Kasih}

Program Studi Ilmu Komunikasi dan Program Studi Manajemen mengucapkan terima kasih kepada Lembaga Pengabdian Masyarakat Universitas Bakrie yang telah mendanai dan memfasilitasi kegiatan PkM ini, kepada Dinas Perindustrian Perdagangan, Koperasi, Usaha Kecil dan Menengah Kota Cirebon yang telah memfasilitasi tempat acara dan berkoordinasi dengan para pelaku UMKM, Universitas Swadaya Gunung Jati Cirebon yang membantu merealisasikan kegiatan ini sebagai bentuk implementasi kerjasama berdasarkan MoU - Memorandum of Understanding dengan Program Studi IImu Komunikasi Universitas Bakrie.

\section{Daftar Pustaka}

Anonim. Potensi Koperasi dan UMKM [Internet]. [Diakses pada 9 September 2019]. Tersedia pada: http://disperindagkopumkm.cirebonkot a.go.id/potensi-koperasi-dan-umkm/

Belch, George E \& Belch, Michael A. 2004. Advertising and Promotion: An Intergrated Marketing Communication Perspective. America: McGraw-Hill Companies

Bohang, Fatimah Kartini. 8 Juta UMKM Ditargetkan "Go Online" pada 2019 [Internet]. [Diakses pada 9 September 2019]. Tersedia pada: https://kominfo. go.id/content/detail/11512/8-juta-umk m-ditargetkan-go-online-pada-2019/0/ sorotan_media

Clow, Kenneth E. dan Baack, Donald. 2012. Integrated Advertising, Promotion, and Marketing Communications, $5^{\text {th }}$ Edition. Boston: Prentice Hall.

Dekur. Jadi Kawasan Ekonomi Khusus (KEK), ICSB Siap Kembangkan UKM Cirebon [Internet]. [Diakses pada 9 September 2019]. Tersedia pada:. https://www. beritainspiratif.com/jadi-kawasan-ekon 
omi-khusus-kek-icsb-siap-kembangkanukm-cirebon/

DKIS04. Untuk Ketiga Kalinya Pelaku UMKM di Kota Cirebon Dapatkan Pelatihan Kewirausahaan Berbasis Online [Internet]. [Diakses pada 9 September 2019]. Tersedia pada: http://www. cirebonkota.go.id/untuk-ketiga-kalinyapelaku-umkm-di-kota-cirebon-dapatkan -pelatihan-kewirahusahaan-berbasisonline/

Egan, John. 2007. Marketing Communications. London: Thomson Learning.

Hanan, Sofhira. 10 Kampung UKM Digital Diresmikan di Cirebon [Internet]. [Diakses pada 9 September 2019]. Tersedia pada: https://www.pikiran-rak yat.com/jawa-barat/2016/08/11/10-ka mpung-ukm-digital-diresmikan-di-cire bon-377223

Ivansyah. Masihkah Cirebon Disebut Kota Udang?. Dalam Tempo, 27 Agustus 2013 [Internet]. [Diakses pada 9 September 2019]. Terdapat pada: https://nasional.tempo.co/read/507686 /masihkan-cirebon-disebut-kota-udang Kotler, Philip dan Keller, Kevin Lane. 2009. Marketing Management, $13^{\text {th }}$ Edition. New Jersey: Pearson
Moriarty, Sandra; Mitchell, Nancy; Wells, William. 2015. Advertising \& IMC: Principles and Practice, $10^{\text {th }}$ Edition. USA: Pearson.

O'Neil, Scheiffer. 2014. An Examinations of Fortune 500 Companies and Philantrophy $200 \quad$ Nonprofit Organizations' Relationship Cultivation Strategies on Facebook. Texas: PRSA

Shimp, Terence A. 2007. Advertising, Promotion, and Other Aspects of Integrated Marketing Communications, 7th Edition. USA: Thomson SouthWestern

Widiastuti, Tuti. 2019. Co-Cultural Reflections on The (Un)Sustainability of a Decentralized Wastewater Treatment System for The Urban Poor in Petojo Utara, Jakarta. Bulletin of the Transilvania University of Braşov, 12(61): 365-374.

Yudhianto. 132 Juta Pengguna Internet Indonesia, 40\% Penggila Medsos [Internet]. [Diakses pada 9 September 2019]. Tersedia pada: https:// inet.detik.com/cyberlife/d-3659956/132 -juta-pengguna-internet-indo nesia-40penggila-medsos

Zarella, Dan. 2010. The Social Media Marketing Book. USA: O'Reilly Media, Inc. 
Indonesian Journal of Social Responsibility (IJSR) Vol. 1, No. 2, (2019), hal. 61-67 